11

\title{
Анализ температурной зависимости спектров экситонной люминесценции квантовых точек селенида кадмия, выращенных в жидкокристаллической матрице*
}

\author{
(C) К.А. Магарян ${ }^{1,2}$, К.Р. Каримуллин ${ }^{1,2}$, И.А. Васильева ${ }^{1}$, А.В. Наумов ${ }^{1,2}$ \\ ${ }^{1}$ Московский педагогический государственный университет, \\ 119435 Москва, Россия \\ ${ }^{2}$ Институт спектроскопии РАН, \\ 108840 Троицк, Россия \\ e-mail: ka.magaryan@mpgu.edu
}

Поступила в редакцию 24.09.2018 г.

Проанализированы температурные зависимости положения максимумов экситонных полос в спектрах люминесценции жидкокристаллических нанокомпозитов с квантовыми точками CdSe с размерами 1.8 и $2.3 \mathrm{~nm}$ при $T=77-300 \mathrm{~K}$. Анализ в рамках теоретической модели, учитывающей электрон-фононное взаимодействие внутри квантовых точек, дал возможность вычислить значения фактора Хуанга-Риса и среднюю энергию фононов в исследуемых нанокристаллах.

DOI: $10.21883 /$ OS.2019.01.47052.283-18

\section{Введение}

Полупроводниковые (коллоидные) квантовые точки (КТ) и композитные структуры на их основе обладают уникальными спектральными и фотофизическими свойствами. Нанокомпозиты с квантовыми точками широко используются в самых различных областях современной науки и технологий (см., например, $[1,2])$. В настоящее время на основе материалов с квантовыми точками производят эффективные и экономичные светоизлучающие устройства, криптографические люминесцирующие покрытия и метки для защиты ценных документов, бланков и других объектов от подмены или подделки. Ведется активный поиск новых сред для лазерной генерации, фотовольтаических элементов и устройств наноэлектроники. Флуоресцентные метки на основе полупроводниковых квантовых точек чрезвычайно востребованы в биологии, медицине и различных диагностических методиках в качестве многопараметрических наносенсоров, поскольку их спектральные свойства (например, кинетика люминесценции) существенно определяются параметрами локального поля, зависят от термодинамических параметров системы и внешних полей (см., например $[3,4]$ ). В частности, квантовые точки применяются в качестве температурных сенсоров [5]. Для использования полупроводниковых нанокристаллов в качестве сенсоров температуры необходимо фундаментальное понимание динамических процессов, определяющих фотофизические свойства квантовых точек [6], и их связи с температурой образца.

Одним из наиболее способов исследования фотофизических характеристик люминофоров различной при-

* XIII International Conference on Hole Burning, Single Molecule, and Related Spectroscopies: Science and Applications (HBSM-2018), August 6-12, 2018, Suzdal-Moscow, Russia. роды является спектроскопия примесного центра. Люминесцирующие излучатели (органические молекулы, квантовые точки), будучи внедренными в твердотельные матрицы, являются удобной модельной средой, обеспечивающей доступ к селективно возбуждаемым однородным спектрам объектов, вплоть до единичных излучателей [7-9].

Температурные зависимости спектров поглощения и флуоресценции различных квантовых точек $(\mathrm{CdSe}, \mathrm{CdS}$, InAs и др.), внедренных в кристаллические растворы, исследовались экспериментально в ряде работ (см., например, [10-12]). В одной из недавних публикаций [13] описывается модель, позволяющая учесть влияние электрон-фононного взаимодействия на температурное поведение спектров люминесценции полупроводниковых нанокристаллов. Сопряженные спектры поглощения и люминесценции жидкокристаллических (ЖК) растворов каприлата кадмия с квантовыми точками селенида кадмия размером 1.8 и $2.3 \mathrm{~nm}$ в широком диапазоне низких температур были экспериментально исследованы в работах [14-16]. Представляет интерес проанализировать смещение максимумов полос экситонной люминесценции для данных образцов при изменении температуры от 77 до $300 \mathrm{~K}$ с учетов влияния процессов электронфононного взаимодействия.

\section{Анализ низкотемпературных спектров люминесценции стеклованных нанокомпозитов}

Спектры поглощения и возбуждения флуоресценции, а также спектры люминесценции для двух ЖК нанокомпозитов с квантовыми точками селенида кадмия размером $1.8 \mathrm{~nm}$ и $2.3 \mathrm{~nm}$, измеренные при различных 
Exciton energy, eV

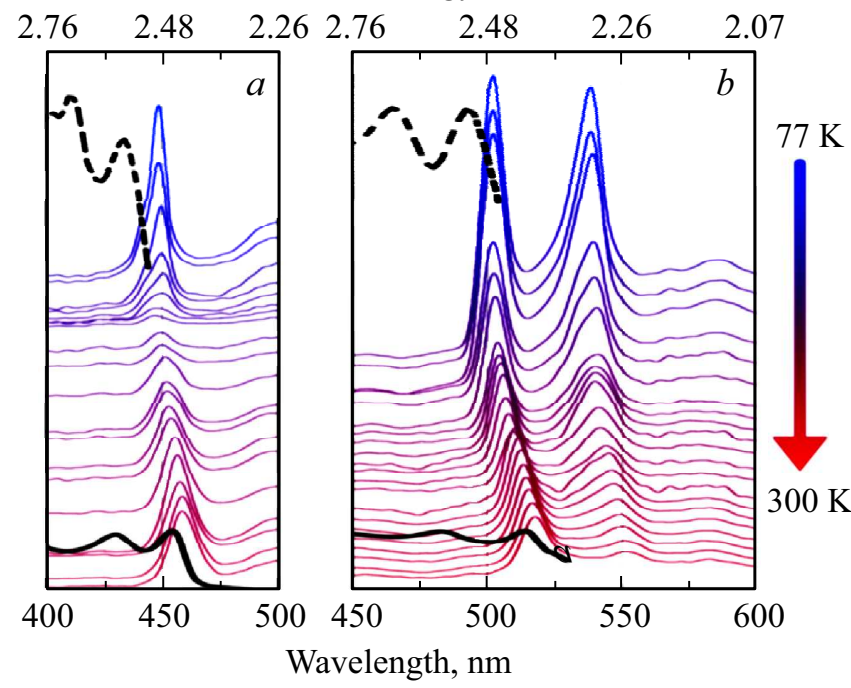

Pис. 1. Низкотемпературные спектры люминесценции ЖК нанокомпозитов с КТ CdSe с размерами $1.8(a)$ и $2.3 \mathrm{~nm}(b)$, спектры поглощения при комнатной температуре (жирные черные кривые внизу), спектры возбуждения флуоресценции при $77 \mathrm{~K}$ (пунктирные кривые вверху).

температурах в диапазоне от $77 \mathrm{~K}$ до комнатной показаны на рис. 1. В спектрах образцов с КТ размером $1.8 \mathrm{~nm}$ наблюдается один экситонный максимум, а для образца с КТ размером $2.3 \mathrm{~nm}$ - два экситонных максимума. В длинноволновой части спектров (не показаны на рис. 1) присутствуют широкие бесструктурные полосы рекомбинационной люминесценции, которые не являются предметом исследования в данной работе. Кроме того, мы будем рассматривать температурную зависимость только для первых экситонных максимумов. Отметим, что анализ возможных механизмов, ответственных за перераспределение интенсивности между отдельными полосами в спектрах люминесценции для двух образцов с разными размерами КТ, выполнен в работе [17].

С понижением температуры максимумы полос экситонной люминесценции смещаются в область высоких энергий. Такую закономерность описывают эффектами электрон-фононного (экситон-фононного) взаимодействия. При этом заметного изменения ширины экситонных максимумов с температурой не наблюдается, что, с одной стороны, связано с разрешающей способностью измерительного оборудования, а с другой - с наличием значительного неоднородного уширения спектров, вызванного большой дисперсией размеров квантовых точек.

Зависимость величины энергия экситона, измеренной по положению экситонного максимума в спектре люминесценции, как функция температуры представлена на рис. 2.

Температурный сдвиг экситонного пика может быть описан с использованием формулы Варшни [18], модифицированой О. Доннеллом и Ченом (О. Donnell and
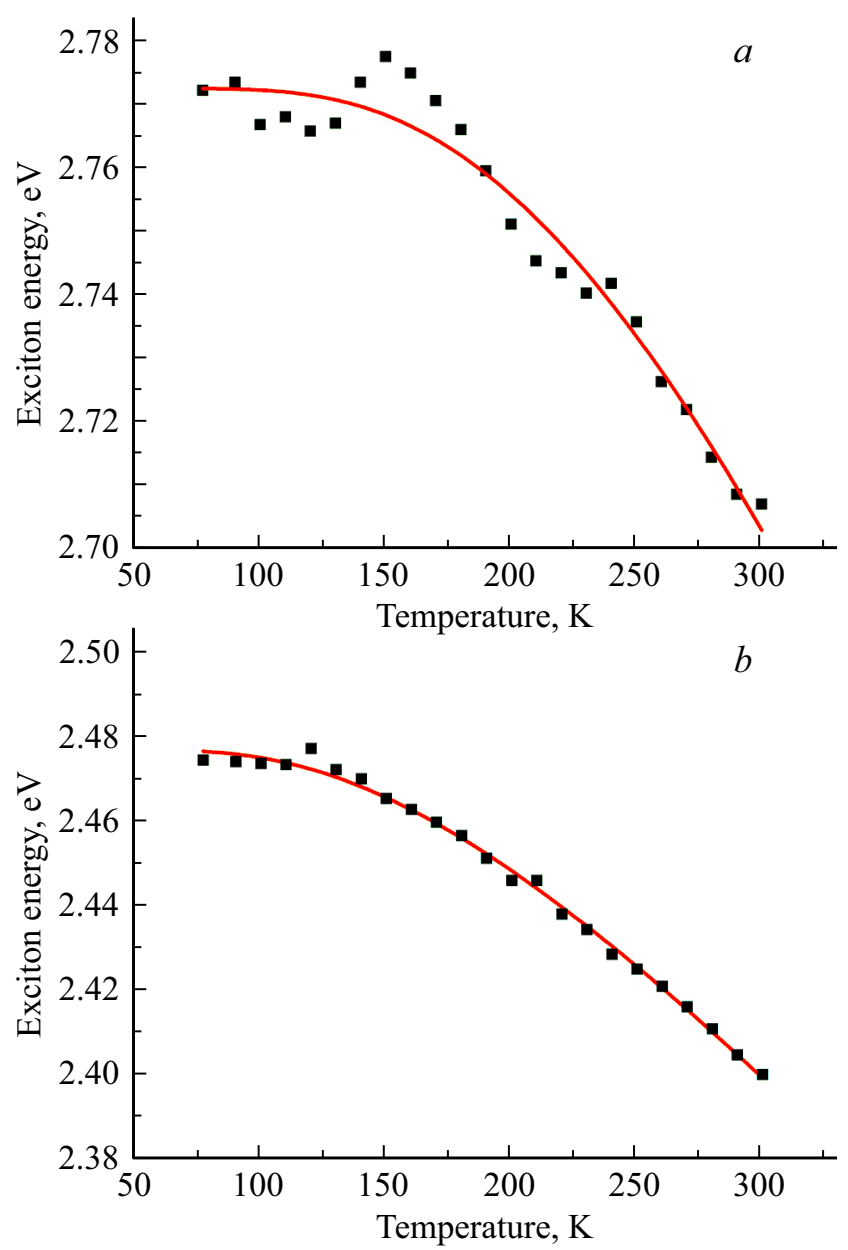

Рис. 2. Температурные зависимости положения первого максимума в спектрах люминесценции (энергии экситона) нанокомпозитов с КТ размерами $1.8(a)$ и $2.3 \mathrm{~nm}(b)$ - точки, и их аппроксимация (сплошные линии) с использованием формулы (1), учитывающей электрон-фононное взаимодействие в КТ.

Значения параметров электрон-фононного взаимодействия для КТ, выращенных внутри ЖК нанокомпозитов.

\begin{tabular}{c|c|c|c}
\hline $\begin{array}{c}\text { Размер квантовых } \\
\text { точек в образце, } \mathrm{nm}\end{array}$ & $E_{g}(0), \mathrm{eV}$ & $S$ & $E_{\mathrm{LO}}, \mathrm{meV}$ \\
\hline 1.8 & 2.78 & 7.1 & 71 \\
2.3 & 2.48 & 4.1 & 46
\end{tabular}

Chen) [19]:

$$
E_{g}(T)=E_{g}(0)-\frac{2 S E_{\mathrm{LO}}}{\exp \left(\frac{E_{\mathrm{LO}}}{K_{B} T}\right)-1}
$$

где $E_{g}(0)$ - величина запрещенной зоны (положение первого экситонного максимума при $0 \mathrm{~K}), S$ - фактор Хуанга-Риса, ответственный за силу электрон-фононного взаимодействия в нанокристалле, $E_{\mathrm{LO}}-$ средняя энергия фононов, $K_{B}$ - постоянная Больцмана. 
Аппроксимация температурных зависимостей положения экситонных максимумов в спектрах люминесценции с использованием этого уравнения позволяет оценить соответствующие параметры исследованных нанокристаллов (см. табл.). Параметры, полученные при численном моделировании температурной зависимости спектров люминесценции, хорошо согласуются с экспериментальными результатами, что свидетельствует о правильности выбранной модели и достоверности полученных данных.

\section{Заключение}

Использование модели, учитывающей электронфононное взаимодействие, позволило количественно описать температурные зависимости экситонных спектров люминесценции квантовых точек, выращенных внутри ЖК матрицы, и определить значения фактора Хуанга-Риса и среднюю энергию фононов для двух типов (размеров) нанокристаллов. При описании температурного поведения положения и ширины спектров люминесценции примесных центров, как правило, рассматривается взаимодействие электронного перехода примеси с колебательными возбуждениями (фононами) в матрице. В настоящей работе мы никак не учитывали влияние матрицы. Изучение данного вопроса может быть предметом дальнейших исследований.

Работа выполнена при финансовой поддержке Российского научного фонда (проект № 14-12-01415 — исследование температурного поведения спектров люминесценции квантовых точек) и Российского фонда фундаментальных исследований (проект № 18-02-01121 исследование динамических процессов в твердотельных нанокомпозитах). Авторы благодарят д.Х.н. проф. Мирную Т.А. и д.ф.-м.н. проф. Климушеву Г.В. за предоставленные образцы.

\section{Список литературы}

[1] Bao J., Bawendi M.G. // Nature. 2015. V. 523. P. 67. doi 10.1038/nature14576.

[2] Gubin M.Yu., Shesterikov A.V., Karpov S.N., Prokhorov A.V. // Phys. Rev. B. 2018. V. 97. N 8. 085431. doi 10.1103/PhysRevB.97.085431.

[3] Aubret A., Pillonnet A., Houel J., Dujardin C., Kulzer F. // Nanoscale. 2016. V. 8. N 4. P. 2317. doi 10.1039/C5NR06998J.

[4] Naumov A.V., Gorshelev A.A., Gladush M.G., Anikushina T.A., Golovanova A.V., Köhler J., Kador L. // ACS Nano Lett. 2018. doi 10.1021/acs.nanolett.8b01753

[5] Zhang F.J., Wang B., Pang F.F., Wang T.Y. // Proc. SPIE. 2011. V. 7990. 79900R. doi 10.1117/12.888617.

[6] Osad'ko I.S., Eremchev I.Yu., Naumov A.V. // J. Phys. Chem. C. 2015. 119. N 39. P. 22646. doi 10.1021/acs.jpcc.5b04885

[7] Francoeur S., Klem J.F., Mascarenhas A. // Phys. Rev. Lett. 2004. V. 93. N 6. 067403. doi 10.1103/PhysRevLett.93.067403
[8] Наумова Н.Л., Васильева И.А., Осадько И.С., Наумов А.В. // Оптика и спектроскопия. 2005. Т. 98. № 4. C. 585.; Naumova N.L., Vasil'eva I.A., Osad'ko I.S. // Optics and Spectroscopy. 2005. V. 98. N 4. P. 535. doi $10.1134 / 1.1914889$

[9] Наумов А.В. // Успехи физических наук. 2013. Т. 183. № 6. C. 633. doi 10.3367/UFNr.0179.200903n.0322; Naumov A.V. // Physics - Uspekhi. 2013. V. 56. N 6. P. 605. doi 10.3367/UFNe.0183.201306f.0633

[10] Ortner G., Yakovlev D.R., Bayer M., Rudin S., Reinecke T.L., Fafard S., Wasilewski Z., Forchel A. // Phys. Rev. B. 2004. V. 70. N 20. 201301(R). doi 10.1103/PhysRevB.70.201301.

[11] Valerini D., Creti A., Lomascolo M., Manna L., Cingolani R., Anni M. // Phys. Rev. B. 2005. V. 71. N 23. P. 235409. doi 10.1103/PhysRevB.71.235409

[12] Favero I., Berthelot A., Cassabois G., Voisin C., Delalande C., Roussignol Ph., Ferreira R., Gerard J.M. // Phys. Rev. B. 2007. V. 75. N 7. 073308. doi 10.1103/PhysRevB.75.073308

[13] Wen X., Sitt A., Yu P., Toh Y.R., Tang J. // Phys. Chem. Chem. Phys. 2012. V. 14. N 10. P. 3505. doi 10.1039/c2cp23844f

[14] Магарян К.А., Михайлов М.А., Каримуллин К.Р., Васильева И.А., Климушева Г.В. // Изв. РАН. Сер. физ. 2014. Т. 78. № 12. С. 1629. doi 10.7868/S0367676514120199; Magaryan K.A., Mikhailov M.A., Vasilieva I.A., Karimullin K.R., Klimusheva G.V. // Bull. RAS. Phys. 2014. V. 78. N 12. P. 1336. doi 10.3103/S1062873814120193

[15] Magarian K.A., Fedyanin V.V., Karimullin K.R., Vasilieva I.A., Klimusheva G.V. // J. Phys. Conf. Ser. 2013. V. 478. 012007. doi 10.1088/1742-6596/478/1/012007

[16] Magaryan K.A., Mikhailov M.A., Karimullin K.R., Knyazev M.V., Eremchev I.Y., Naumov A.V., Vasilieva I.A., Klimusheva G.V. // J. Lumin. 2016. V. 169. P. 799. doi 10.1016/j.jlumin.2015.08.064

[17] Karimullin K.R, Mikhailov M.A., Georgieva M.G., Magaryan K.A., Vasilieva I.A. // J. Phys. Conf. Ser. 2018. V. 951. 012011. doi 10.1088/1742-6596/951/1/012011.

[18] Varshni Y.P. // Physica. 1967. V. 34. N 1. P. 149. doi 10.1016/0031-8914(67)90062-6

[19] O'Donnell K.P., Chen X. // Appl. Phys. Lett. 1991. V. 58. N 25. P. 2924. doi $10.1063 / 1.104723$ 